\title{
- Como e quando intervir no parto de cadelas
}

\section{- How and when to intervene in the parturition of bitches}

Faculdade de Medicina Veterinária e Zootecnia - UNESP Campus de Botucatu Departamento de Reprodução Animal e Radiologia Veterinária Distrito de Rubiāo Júnior, $\mathrm{s} / \mathrm{n}$ CEP 18.618-000 - Botucatu - São Paulo Fone/Fax: $\left(0^{\star \star} 14\right) 6802-6249$ End. Eletrôn.: rarv@fmvz.unesp.br

Prof. Adjunto da Disciplina de Obstetrícia Veterinária

FMVZ - UNESP/Botucatu/SP.

\section{RESUMO}

Este artigo tem por objetivo caracterizar a fisiologia do parto normal das cadelas, apresentando as formas mais freqüentes das distocias de causa materna e fetal e as alternativas básicas de como e quando fazer a intervenção.

Palavras-chave: cadela, parto, distocia.

\section{Introdução}

tempo empírico de gestação das cadelas é de 63 dias, com variação de 56 a 72 dias, quando calculado da data da primeira cobertura. Essa grande variação deve-se ao longo período de comportamento estral. A duração da prenhez, endocrinologicamente calculada, é muito menos variável, ocorrendo o parto $65 \pm 1$ dias do pico pré-ovulatório de $\mathrm{LH}$, isto é, $63 \pm 1$ dias do momento da ovulação. Variações gestacionais foram descritas relacionando-se ao porte e à raça dos animais, porém essas observações não estão bem documentadas (LINDE-FORSBERG e ENEROTH, 1998).

Ainda não se conhece, de forma clara e definitiva, qual o fenômeno indutor do início do trabalho de parto e por que, ao término do período gestacional, desencadeiase a sequiência de eventos endócrinos que, aliados aos estímulos nervosos e forças mecânicas, determinam a expulsão dos produtos.

A indução do parto ao final da gestação é um procedimento utilizado, em situações particulares, em algumas espécies animais. Nos bovinos, obtêm-se re- sultados com o uso de corticóides e, nos eqüinos, com a utilização da ocitocina ou sua associação com prostaglandinas.

A indução do parto na espécie canina não tem aplicabilidade prática e rotineira, em razão da característica do ciclo estral e do cio, alta viabilidade do esperma depositado no trato genital e do momento da ovulação, o que caracteriza um período de gestação bem típico para esse grupo animal. Sabe-se que a administração de glicocorticóides estimula a produção de estrógeno e de prostaglandina pela unidade feto/placentária. A aplicação de dose única de corticóide não é eficiente para induzir o parto nas cadelas, embora a dexametasona, quando administrada duas vezes ao dia, durante 10 dias, começando um mês após a ovulação, redunda em abortamento. $\mathrm{O}$ mecanismo de ação é ainda desconhecido, porém repetidas aplicações de altas doses torna o método impraticável no uso rotineiro das clínicas.

O primeiro estágio do parto dura de 6 a 12 horas, caracterizando-se por relaxamento cervical e vaginal, por eventual mobilidade dos produtos, alterando a estática fetal, e por ligeira queda de temperatura corporal. $\mathrm{Na}$ segunda etapa, com duração de 3 a 12 horas (rara- 


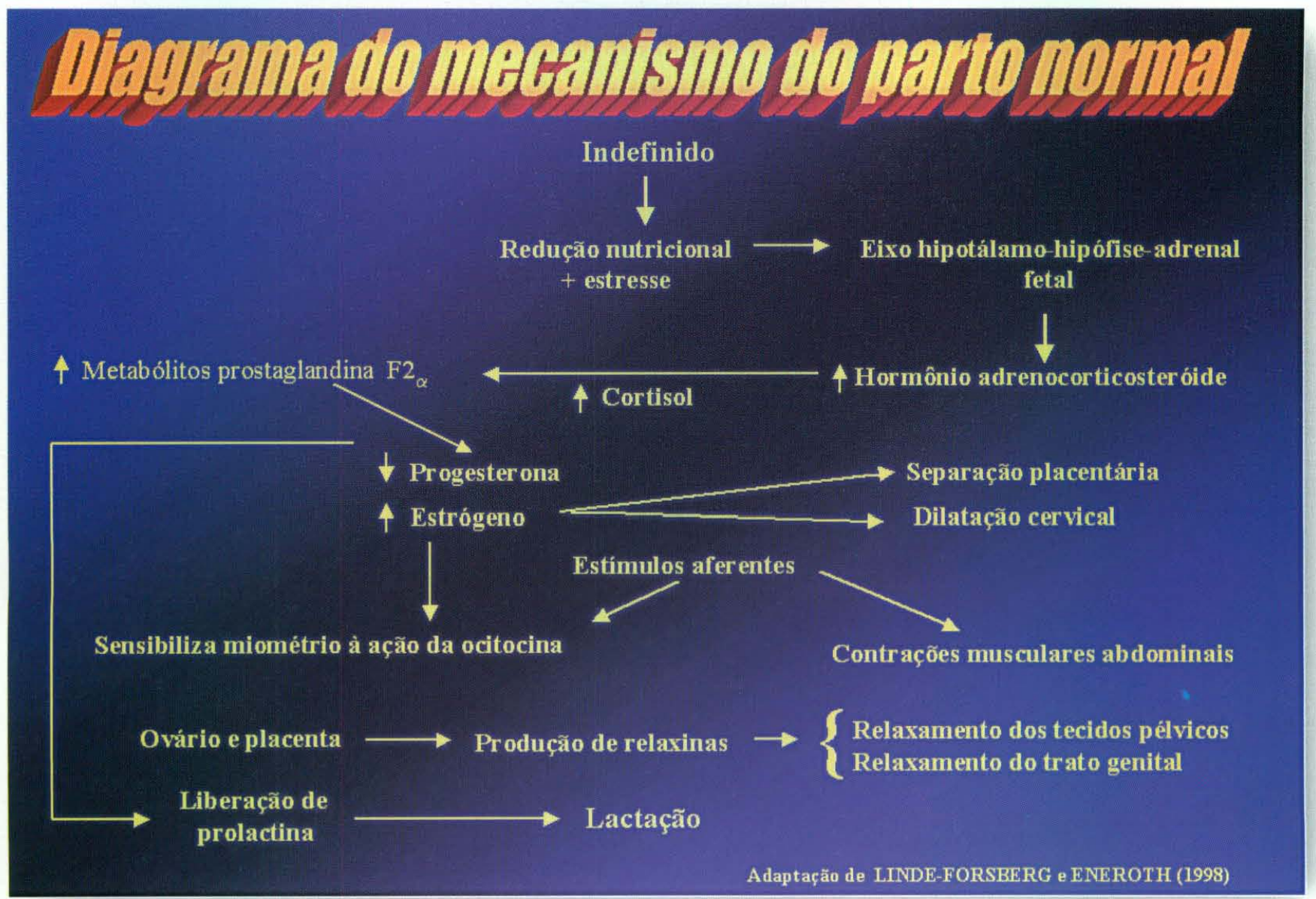

mente 24 horas), ocorre a expulsão dos filhotes pela ação das contrações das musculaturas abdominal e uterina. A temperatura volta ao normal ou permanece ligeiramente abaixo.

No terceiro estágio, acontece a expulsão das placentas se os anexos não forem eliminados concomitante ou logo após ao respectivo filhote. A secreção puerperal imediata tem coloração esverdeada para as cadelas e vermelha ou marrom para as gatas. É esperada a ocor- rência de diarréia nas cadelas que ingerirem os anexos fetais, e a involução uterina integral acontece em 12 a 15 semanas pós-parto.

Distocia: É definida como uma dificuldade de nascer ou a inabilidade materna em expelir os fetos pelo canal do parto, sem assistência. É mais freqüente nas cadelas que nas gatas e, de modo geral, apresenta incidência de $5 \%$, podendo atingir a $100 \%$ em algumas raças,

\section{Examlinar so:}

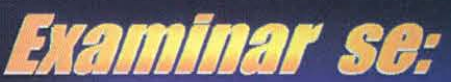

$\checkmark$ Houver corrimento vagina esverdeado, vermelho ou marrom sem expulsão dos produtos há 2 - 4 his.

$\checkmark$ Houver expulsão dos líqüidos devido ruptura das bolsas há2 2 4 hs.

$\checkmark$ A parturiente estiver de bilitada e sem contraçôes há mais de 2 . 4 hs.

$\checkmark$ A parturiente apresentar forte e regular contração há mais de 20 - 30 min. Sem expulsão.

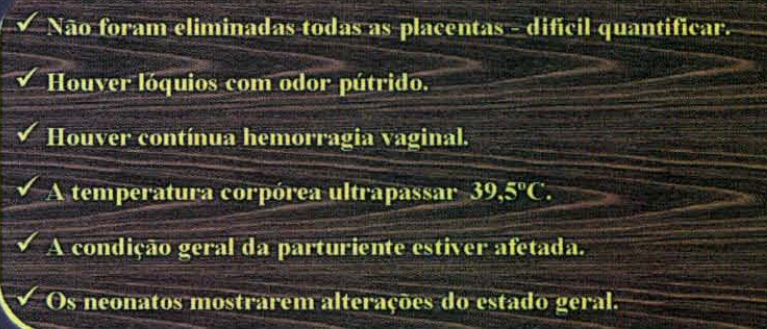




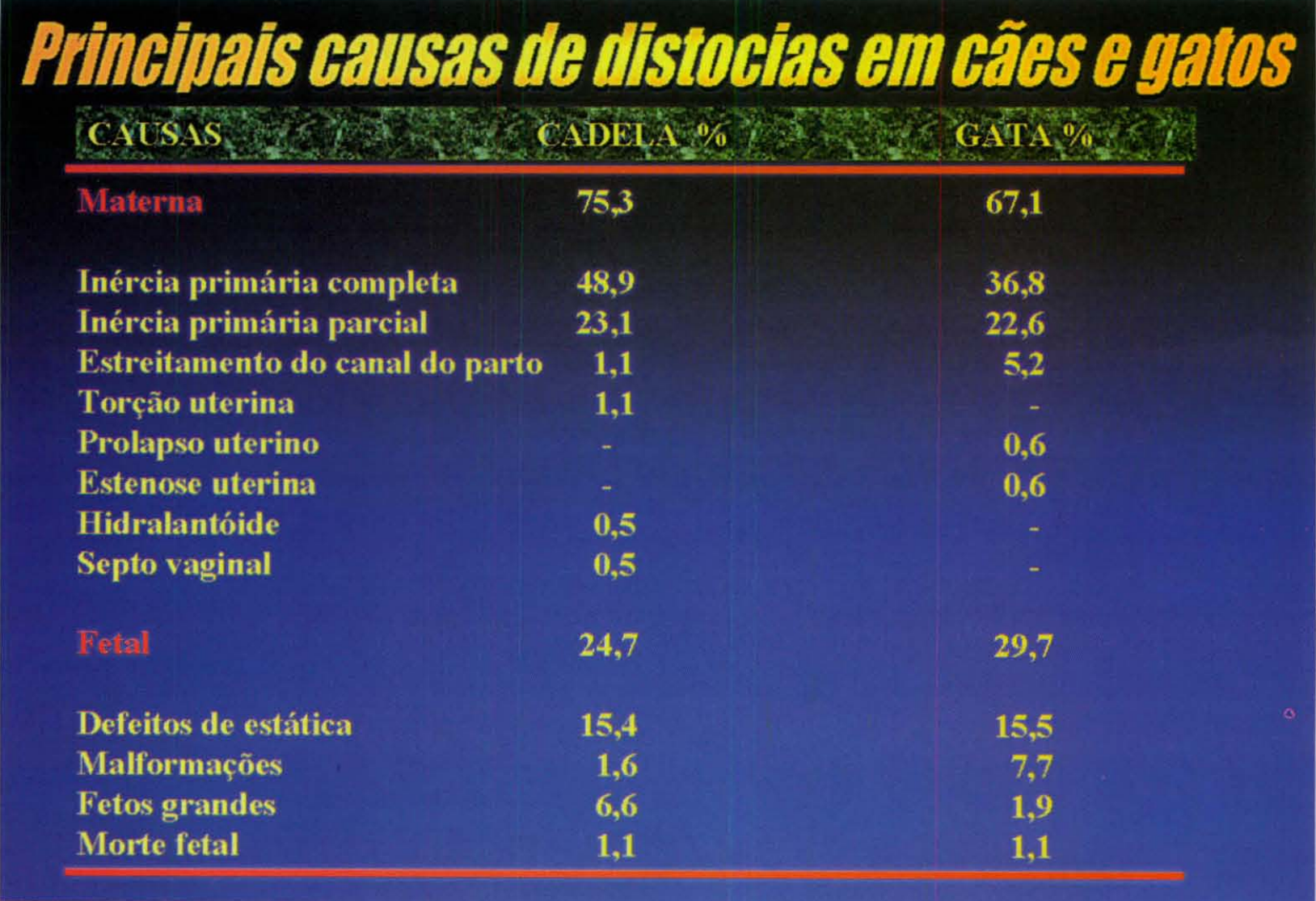

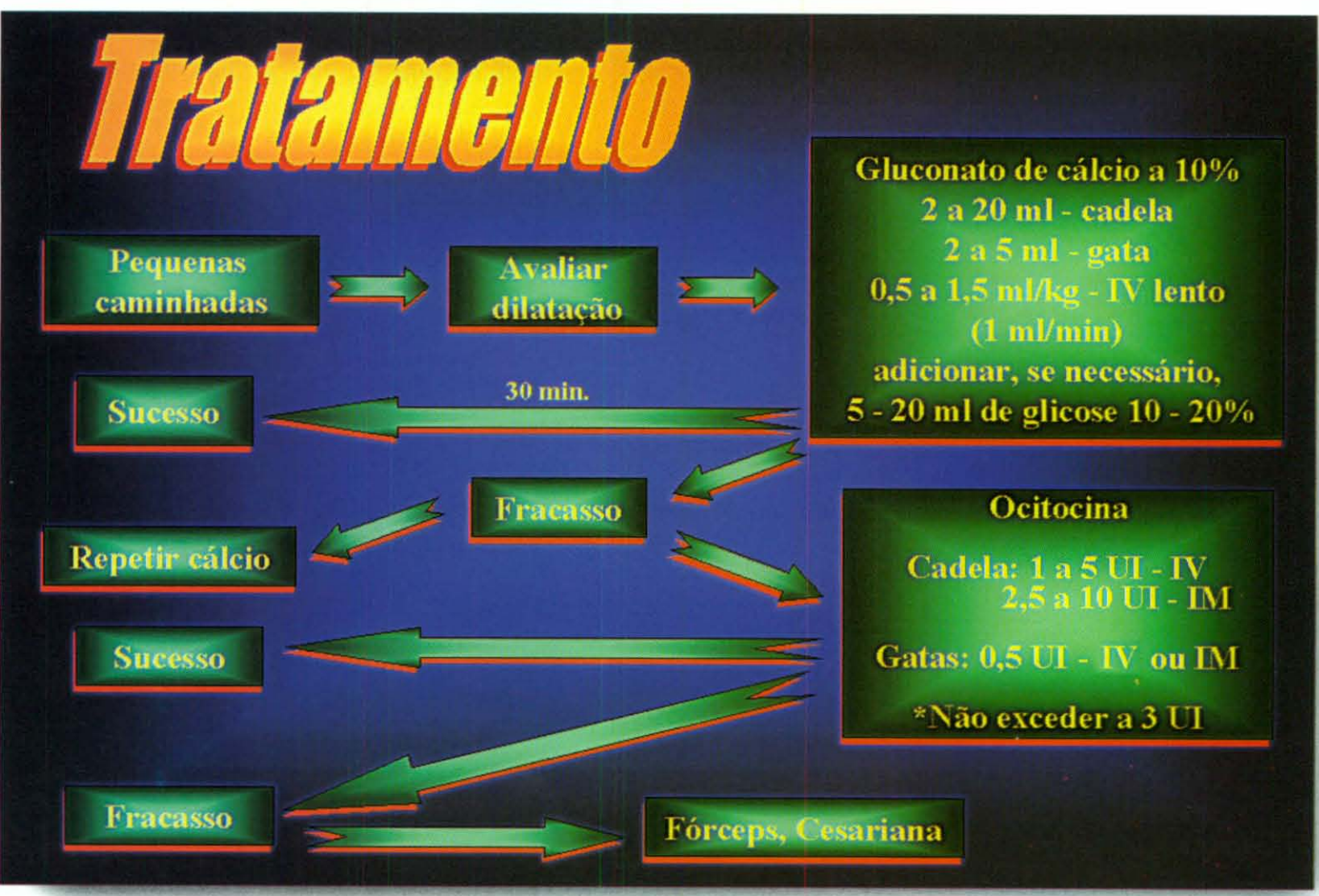


PRESTES, N. C. Como e quando intervir no parto de cadelas / How and when to intervene in the parturition of bitches. / Rev. educ. contin. CRMV-SP / Continuous Education Journal CRMV-SP, São Paulo, volume 4, fascículo 2, p. 60 - 64, 2001.

sendo mais comum nos animais de alta linhagem, quando comparados aos sem raça.

Inércia uterina: é subdividida em primária e secundária, com a seguinte definição:

Primária: quando o útero falha em contrair,

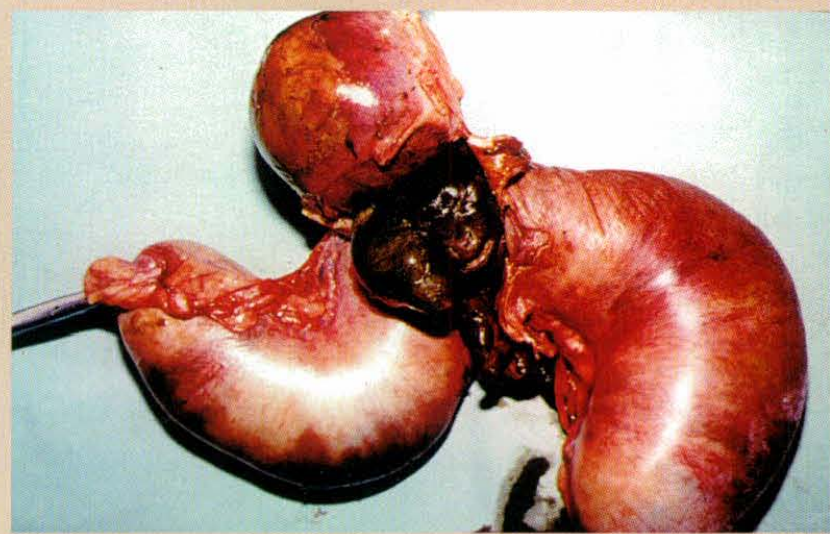

Figura 1. Massa tumoral no corpo uterino, bloqueando a expulsão dos filhotes.

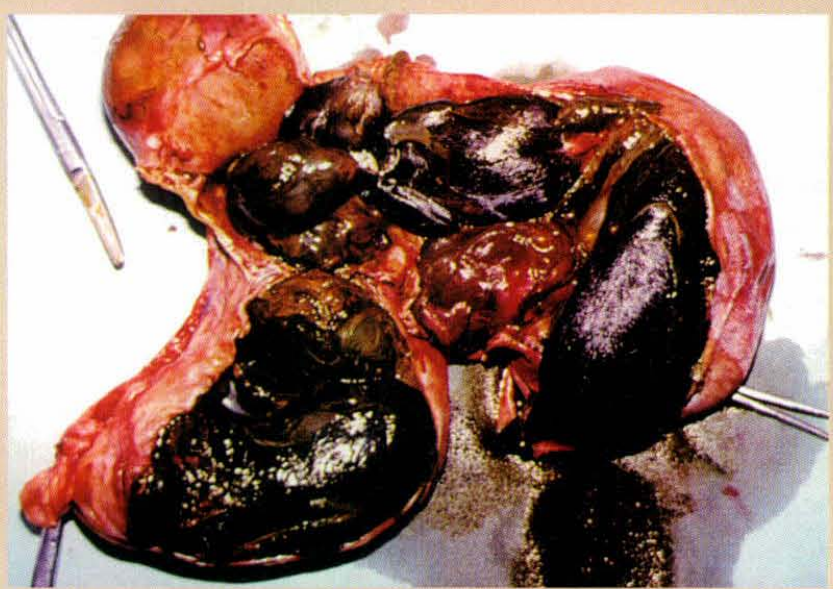

Figura 2. Imagem do útero aberto, exibindo os filhotes mortos e alteração na coloração dos líquidos fetais.

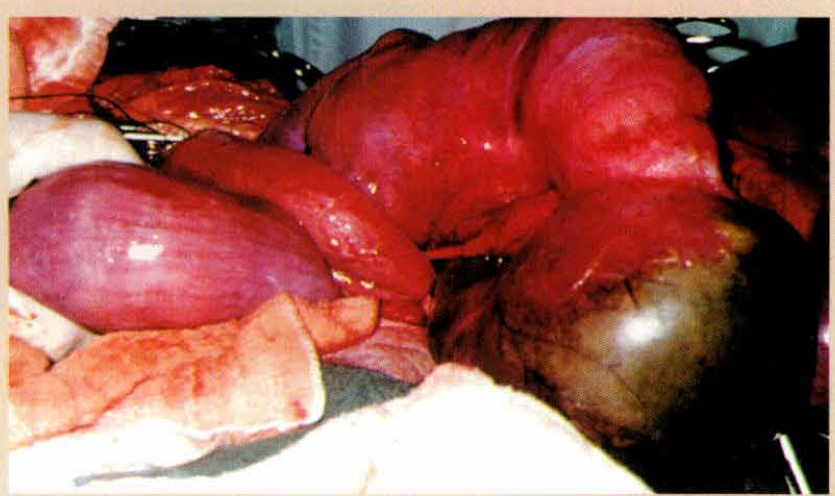

Figura 3. Torção uterina, evidenciando-se início de necrose, em cadela submetida à cesariana. em resposta aos estímulos endógenos característicos do parto. Síndrome do feto único, excesso de líquidos fetais, fetos absolutos ou relativos grandes, distúrbio nutricional, infiltração de gordura, disfunção hormonal ou doenças sistêmica materna, entre outras.

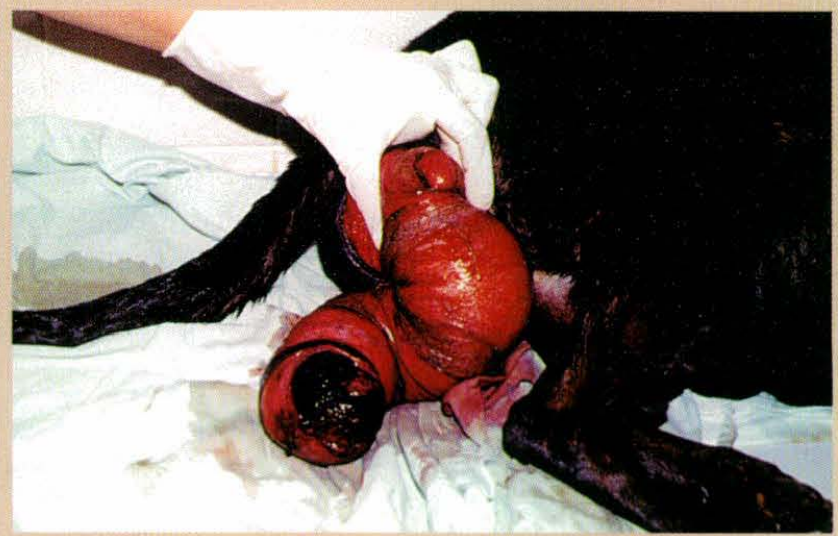

Figura 4. Prolapso total de um corno uterino, durante o parto normal.

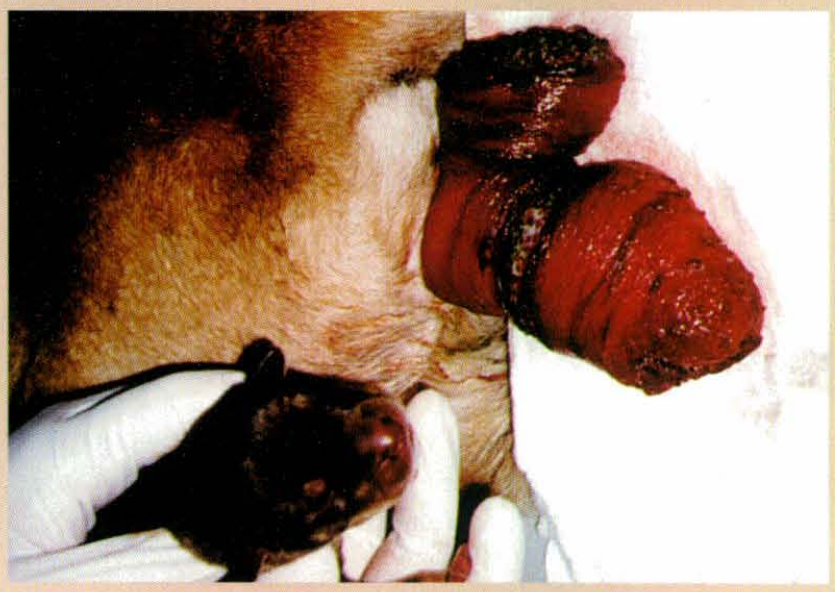

Figura 5. Prolapso parcial de ambos os cornos uterinos, durante a fase expulsiva em cadela. A área anelar mais escura, representa o local da justaposição placentária.

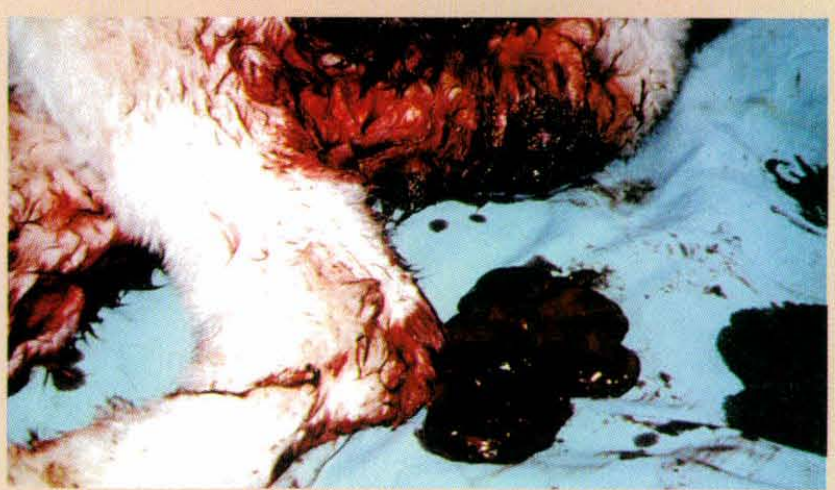

Figura 6. Sinais de hemorragia na via fetal mole, com emissão de coágulos em cadela em trabalho de parto. 
Secundária: devido à exaustão do miométrio, causada por obstrução do canal do parto.

Cuidados especiais devem ser tomados ao utilizar ocitocina. Em alguns animais, promove contrações prolongadas que podem ocasionar a separação precoce da placenta, a estenose cervical e mesmo a ruptura uterina. Ergotaminas de longa ação nunca devem ser utilizadas durante o parto.

O emprego de fórceps em Medicina Veterinária é extremamente limitado. Para os pequenos animais, particularmente para cadelas, sua utilização é desencorajada por se tratar de um procedimento sem controle visual e com indicações restritas aos fetos absolutos e relativos grandes ou outras situações especiais. Os profissionais, de forma geral, utilizam-se da cesariana como meio de finalizar um parto laborioso.

\section{Operação cesariana}

\section{Indicações:}

- Inércia uterina primária completa, que não responde ao tratamento;

- Inércia uterina primária parcial, refratária ao medicamento;

- Inércia uterina secundária;

- Estenoses pélvicas ou da via fetal mole;

- Fetos absolutos ou relativos grandes;

- Excesso ou deficiência de líquidos fetais;

- Defeitos de apresentação, posição ou atitude;

- Morte fetal / decomposição;

- Toxemia da gestação ou doenças da parturiente;

- Negligência;

- Profilática.

\section{SUMMARY}

The objective of this paper is to characterize the physiology of normal parturition in bitches. Special emphasis is given to the more common maternal and fetal dystocias as well as to the basic alternatives on how and when to intervene.

Key words: bitch, parturition, dystocie.

\section{BIBLIOGRAFIA DE APOIO}

1. CONCANNON, P. W.; McCANN, J. P.; TEMPLE, M. Biology and endocrinology of ovulation, pregnancy and parturition in the dog. Journal of Reproduction and Fertility, v. 39, p. 3-25, 1989. Supplement.

2. EKSTRAND, C.; LINDE-FORSBERG, C. Dystocia in the cat: a retrospective study of 155 cases. Journal of Small Animal Practice, v. 35, n. 8, p. 459-464, 1994.

3. DARVELID, A. W.; LINDE-FORSBERG, C. Dysticia in the bitck: a retrospective study of 182 cases. Journal of Small Animal Practice, v. 35, n. 8, p. 402-407, 1994.

4. FIENI, F.; DUMON, C.; TAINTURIER, D.; BRUYAS, J. F. Clinical protocol for pregnancy termination in bitches using prostaglandin F2a. Journal of Reproduction and Fertility, v. 51, p. 245-250, 1997. Supplement.
5. GAUDET, D. A. Retrospective study of 128 cases of canine dystocia. Journal of the American Animal Hospital Association, v. 21, n. 6, p. 813-816, 1985.

6. KUNIYUKI, A. H.; HUGHES, M. J. Pregnancy diagnosis by biochemical assay. Problems in Veterinary Medicine-Canine Reproduction, v. 4, n. 3, p. 505-530, 1992.

7. LALIBERTE, L. Pregnacy, obstetrics and postpartum management of the queen. In: MORROW, D. A. Current therapy in theriogenology: diagnosis, treatment and prevention of reproductive disease in small and large animals. 2. ed. Philadelphia: W. B. Saunders, 1986. p. 812-821.

8. LINDE-FORSBERG, C.; ENEROTH, A. Manual of small animal reproduction and neonatology. Shurdington: British Small Animal Veterinary Association, 1998. p. 126-142.

9. RONSIN, P.; BERTHELOT, X. Aborto provocado em cadelas. A Hora Veterinária, ano 16, n. 94, p. 68-73, 1996. 